\title{
Phytochemical Analysis and Determination of Vitamin Contents of Geranium Robertianum
}

\author{
Igwenyi, I. O. \& Elekwa, A. E.
}

\begin{abstract}
Geranium robertianum is one of the garden plants with leaves that are used by some indigenous people in Eastern Nigeria as a medicinal herb. In this study, the phytochemical analysis and vitamins content such as vitamins $(A, B, C, D$ and $E)$ analysis were carried out using standard analytical methods in order to determine their various levels as a prelude to its biochemical activity and possible applications. The mean concentration values of the phytochemicals in $\mathrm{mg} / 100 \mathrm{~g}$ were flavonoids $4.266 \pm 0.10$, tannin $3.67 \pm 1.5$, saponin $1.43 \pm 0.06$, alkaloid $1.200 \pm 0.10$, oxalate $1.002 \pm 0.03$ and phenol $0.03 \pm 0.02$. The mean concentration values of vitamins: $A, B_{1}, B_{2}, B_{3}, C$ and $E$ were $1.44 \pm 0.02,288.17 \pm 0.12,818.21 \pm 0.07,319.13 \pm 0.12,14.76 \pm 5.1$, $0.016 \pm 0.02 \mathrm{mg} / 100 \mathrm{~g}$ respectively. The presence of vitamins and bioactive components are indicative of possible therapeutic and medicinal application.
\end{abstract}

\section{Introduction}

Herbalism is a traditional medicine or folk medicine practice based on the use of plants and plant extracts. It is also known as botanical medicine, medical herbalism, herbal medicine, herbology and herblore (Fabricant and Farnsworth, 2001). Plants have evolved the ability to synthesize chemical compounds that help them defend against attack from a wide variety of predators, such as insects, fungi and herbivorous mammals. By chance, some of these compounds whilst being toxic to plant predators treat human diseases (Lai and Roy, 2004)

Africa is endowed with so many of such plants that can be used for medicinal purposes to which they have taken free advantage. In fact, out of the approximated 6400 plant species used in tropical Africa, more than 4,000 are used as medicinal plants (Stanley, 2009).

Phytochemicals are plant secondary metabolites that have been used as drugs for millennia. Tannins are phenolic compounds, widely distributed in many species of plants where they play a role in protection from predators and perhaps also as pesticides and in regulating plant growth (Ferrel and Thorington, 2006) and they coagulate gelatin and other proteins by binding to them and precipitating them (George and Pampleona, 2002). They also inhibit activities of some enzymes such as trypsin, chymotrypsin, amylase and lipase (Griffths, 1999).

Flavonoids (both flavonols and flavanols) are most commonly known for their antioxidant activity in vitro. At high experimental concentrations that would not exist in vivo, the antioxidant abilities of flavonoids in vitro may be stronger than those of vitamins $\mathrm{C}$ and $\mathrm{E}$ depending on concentrations tested. Consumers and food manufacturers' have become interested in flavonoids for their possible medicinal properties, especially their putative role in inhibiting cancer or cardiovascular disease (Bagchi et al., 1999).

Alkaloids regulate plant growth (Aniaszekwski, 2007), used in medicine usually as psychoactive drugs; cocaine and cythinone are stimulants of the central nervous system, mescaline and many of indole alkaloids have hallucinogenic effect (Veselovskaya, 2000), while morphine and codeine are strong narcotic pain-killers (Cordell, 2001). Saponins are often bitter to taste and so can reduce palatability (e.g. in live stock feeds) or even imbue them with life-threatening animal toxicity as they destroy red blood corpuscles by haemolysis. Data has shown that some saponins are toxic to cold-blooded organisms and insects at a particular concentration (Hostettmann and Morston, 1995).

Spices are known to significantly contribute to the flavour, taste and medicinal properties of food because of phenolics such as tannic, gallic, vanillic acids etcetera (Bocobza, and Aharoni, 2008) and some are believed to be cancer chemopreventives, decreasing the risk of developing cancer. An example is Epigallocatechin-3 gallate, found in green tea (Dea, 2002).

In the body, oxalic acid combines with divalent metallic cations such as calcium $\left(\mathrm{Ca}^{2+}\right)$ and iron $\left(\mathrm{Fe}^{2+}\right)$ to from crystals of the corresponding oxalates which can form larger kidney stones that can obstruct the kidney tubules. An estimate $80 \%$ of kidney stones are formed from calcium oxalates (Coe et al., 2005).

Vitamins are organic compounds required as vital nutrients in tiny amounts by an organism. Vitamins serve as biocatalysts in many chemical reactions as well as precursors to various body factors. They also required for a variety of biological processes such as mental alertness e.g niacin; resistance to infections e.g. vitamin C. Vitamin A is necessary in vision (McGuire and Beerman, 2007; Combs, 2008), gene transcription 
(Combs, 2008; Duester, 2008), immunity (Semba, 2001), dermatology (Nelson et al., 2008), growth and development (Solomon, 2001) and so on.

Thiamine derivatives and thiamine dependent enzymes are present in all cells of the body, thus a thiamine deficiency would seem to adversely affect all of the organ systems. However, the nervous system and the heart are particularly sensitive to thiamine deficiency because of their high oxidative metabolism (Butterworth, 2006).

The Geranium plant is used in South Africa for healing wounds, abscesses; cold sores, sore throats and infections. It is often recommended traditionally for diarrhea and dysentery (Ericksen, 2000). The part of the geranium plant mostly used is its leaves. Pelargoniums were used in south Africa cultures as a traditional medicine for healing wounds, abscesses cold sores, sore throats aid in infections, and continue to have a wide array of uses in the garden, kitchen and medicine cabinet. Recent studies confirm that geranium oil dramatically reduces pain following an outbreak of shingles (Ericksen, 2000).

In Ebonyi State of Nigeria, the plant leaves are used as vegetable in soup, stew and potage preparations especially for people recovering from abortions, child delivery and loss of blood. The indigenous people believe that the leaves have anti-anemic properties. This work was aimed at determining the quantitative phytochemical analysis and vitamin $\mathrm{A}, \mathrm{B}_{1}, \mathrm{~B}_{2}, \mathrm{~B}_{3}$, E, and $\mathrm{E}$ contents of the Geranium robertianum fresh leaves.

\section{Materials And Methods}

MATERIALS: Fresh leaves of the plant were collected from F-41 Democracy Housing Estate, Abakaliki where the plant was planted as an ornamental and hedge forming plant. The fresh leaves were thoroughly washed with fresh water under a fast running tap and later rinsed with distilled water. They were macerated and used for the analyses.

METHODS: Standard spectrophotometic and titrimetric methods were used in the determination of phytochemical contents of the Geranium robertianum leaves. Flavonoids were determined using the methods of Boham and Kocipai, (1994), saponins, phenols and glycosides (Obadoni and Ochuko, 2001), alkaloids by Harbone (1973), oxalates and tannins by titrimetric methods of Onwuka (2005). Standard spectrophotometric methods of AOAC (1990) and Okwu (2004) were used in the determination of all the vitamin contents of the leaves except vitamin $\mathrm{C}$ that was determined using titrimetric method (Okwu, 2004).

\section{Results}

Table 1: PHYTOCHEMICAL ANALYSIS OF GERANIUM PLANT

\begin{tabular}{|c|c|}
\hline Phytochemical & Concentration $(\mathbf{m g} / \mathbf{1 0 0 g})$ \\
\hline Alkaloid & $1.20 \pm 0.10$ \\
\hline Saponin & $1.43 \pm 0.06$ \\
\hline Flavonoid & $4.266 \pm 0.10$ \\
\hline Tannin & $3.670 \pm 1.15$ \\
\hline Phenol & $0.030 \pm 0.02$ \\
\hline Glycoside & $0.20 \pm 0.06$ \\
\hline Oxalate & $1.002 \pm 0.03$ \\
\hline
\end{tabular}

Table 1 shows the different phytochemicals and their various concentrations. It was observed that the flavonoid content was highest at a value $4.266 \pm 0.10$ followed by tannin at $3.67 \pm 1.15$, while the value of saponin $1.43 \pm 0.06$, alkaloid $1.20 \pm 0.10$, oxalate $0.10 \pm 0.03$, glycoside, $0.203 \pm 0.06$ with phenol having the least value of $0.03 \pm 0.02 \mathrm{mg} / 100 \mathrm{~g}$.

Table 2: VITAMIN ANALYSIS

\begin{tabular}{|c|c|}
\hline Vitamin & Concentration (mg/100g) \\
\hline Vitamin A & $1.44 \pm 0.02$ \\
\hline Vitamin $\mathrm{B}_{1}$ & $288.17 \pm 0.12$ \\
\hline Vitamin $\mathrm{B}_{2}$ & $818.21 \pm 0.07$ \\
\hline Vitamin $\mathrm{B}_{3}$ & $319.13 \pm 0.12$ \\
\hline Vitamin C & $14.76 \pm 5.1$ \\
\hline Vitamin E & $0.016 \pm 0.02$ \\
\hline
\end{tabular}

Table 2 shows the different vitamin concentration contained in Geranium robertianum leaves. It was observed that the $\mathrm{B}$ complex family were high, with vitamin $\mathrm{B}_{2}$ having the highest concentration of $818.21 \pm 0.07$, followed by vitamin $B_{3} 319.13 \pm 0.2$ and vitamin $B_{1}$ having $288.17 \pm 0.12$. The plant also contains significant amounts of vitamin $C$ and vitamin A $14.76 \pm 5.1$ and $1.44 \pm 0.02$ respectively while vitamin $E$ content had the least value $0.016 \pm 0.02 \mathrm{mg} / 100 \mathrm{~g}$, thus have a predominance of water- soluble vitamins. 


\section{Discussion}

Indigenous people have employed geranium plant over the years unconsciously without knowing the reasons why it is believed to be divine in various health applications. In this research, the phytochemical analysis and determination of the vitamin contents were carried out to evaluate its chemical composition.

The phytochemical study of Geranium robertianum as shown in table 1 indicates that it has high antioxidant effect with the flavonoid content of $4.266 \pm 0.01 \mathrm{mg} / 100 \mathrm{~g}$. Flavonoids are potent water-soluble antioxidants and free radical scavengers, which prevent oxidative cell damage, have strong anticancer activity (Salah et al., 1995; Del-Rio et al., 1997; Okwu, 2004). Flavonoids in intestinal tract lower the risk of heart disease. As antioxidants, flavonoids from these plants provide anti-inflammatory activity (Okwu, 2004).

Saponin had concentration of $1.43 \pm 0.06 \mathrm{mg} / 100 \mathrm{~g}$ and has the property of precipitating and coagulating red blood cells (Francis et al., 2002). Some of the characteristics of saponins include formation of foams in aqueous solutions, hemolytic activity, cholesterol binding properties and hemolytic activity, and bitterness (Okwu, 2004). These properties bestow high medicinal value on the extract from geranium (Okwu and Okwu, 2004).

Apart from saponins, other secondary metabolite constituents of geranium present include the alkaloids and phenols. Pure isolated alkaloids and their synthetic derivatives are used as basic medicinal agents for their analgesic, antispasmodic and bactericidal effects (Okwu and Okwu, 2004). They exhibit marked physiological activity when administered to animals (Okwu, 2004).

The presence of phenolic compounds in this plant indicates that these plants may be used as an anti-microbial agent. This agreed with the findings of Ofokansi et al., (2005) who reported that B. pinnatum is effective in the treatment of typhoid fever and other bacterial infections, particularly those caused by Staphylococcus aureus, Esherichia coli, Bacillus subtilis, Pseudomonas aeruginosa, klebsiella aerogenes, klebsiella pneunoniae and Salmonella typhi. These findings supported the use of B. pinnatum in treating the placenta and navel of newborn baby, which not only heals fast but also prevent the formation of infections (Okwu, 2001; Okwu, 2003).

The tannin content of the herb is speculated to account for the observed anti-inflammatory activity of the plant material. It exerts anti-inflammatory effects probably by inhibiting the release, synthesis and /or production of inflammatory cytokines and mediators, including prostaglandins, histamine, polypeptide kinins and so on (Ojewole, 2005). Tannins have astringent properties, hasten the healing of wounds and inflamed mucous membranes. These perhaps, could also explain why traditional medicine healers in Southeastern Nigeria often use herb in treating wounds and burns (Agoha, 1974). Tannins are also reported to have various physiological effects like anti-irritant, anti-scretolytic anti-parasitic and anti-microbial activities. Plants containing tannin are used to treat non-specific diarrhea and inflammation of the mouth (Ofokansi et al,. 2005). When incubated with red grape juice and red wines with a high content of condensed tannins, the poliovirus, herpes simplex virus, and various enteric viruses are inactivate (Schmitt et al., 2003).

The scratchy nature of the fluid from the geranium plant could be attributed to the oxalate level being $1.002 \pm 0.03 \mathrm{mg} / 100 \mathrm{~g}$. According to Iwuoha and Kalu, some of the anti-nutritional and off-flavour problems (bitter and astringent taste and scratches in the mouth and throat associated with cocoyam are caused y calcium oxalate (raphids).

As a plant; geranium contains high levels of vitamin $\mathrm{B}$ complexes which are water soluble vitamins: Vitamin $B_{1} 288.17 \pm 0.12 \mathrm{mg} / 100 \mathrm{~g}$; vitamin $B_{2} 818.21 \pm 0.07 \mathrm{mg} / 100 \mathrm{~g}$ and vitamin $B_{3} 319.13 \pm 0.12 \mathrm{mg} / 100 \mathrm{~g}$. So Geranium robertianum is a good source vitamin B complex and can be used or maintaining health in humans and animals (Ball, 2006).

Vitamin A content in the Geranium robertianum plant is $1.44 \pm 0.02 \mathrm{mg} / 100 \mathrm{gg}$ and as such, can be a good source of retinol. Vitamin $\mathrm{E}$ has the least value in the geranium plant. $0.016 \pm 0.02$ but not withstanding, it still has a major role to play when taken into the body as as a signaling molecule and also aids in inhibition of platelet aggregation (Zingg, 2008)

\section{Conclusion}

The need to explore and develop geranium plant is urgent, especially in the view of the rapidly growing need for improvement in the medicine. More so, the plant, if developed can be of immense use to both pharmaceutical and cosmetic industries, since it contains bioactive compounds. This research has shown that the plant has high nutritional and medicinal properties. However, the important aspect in using herbal extracts and their formulation is the quality assurance of the herbal preparations so as to ensure their safety and efficiency; the traditional use of geranium or its extracts is not an exception; therefore care must be taken when using the plant or its extracts as food or therapeutics.

Further research is suggested in order to develop in update method of processing, formulating and assurance of good quality and safety of the products. 


\section{References}

[1] Agoha, R.C. (1974). Medicinal Plants of Nigeria. Offset Drakkerij.Faculfcitder Wiskunde in Naturwetenschappen, the Netherlands , 41 and 33 .

[2] Aniszewki, T. (2007). Alkaloid secrets of life. Amsterdam press, Elsevier., 78-99.

[3] Bagchi, M., Mark., B., Xumei, Y., Sidney S. and Debasis B. (1999). Acute and chronic Stress-Induced Oxidative gastrointestinal injury to fats and the protective ability of a novel grape seed proanthocyanidin extract. Nutrition Research; 19 (8):

[4] Ball F.G. (2006). Riboflavin in vitamins in foods analysis: Bioavailability and stability Taylor and Francis group, USA. $168-173$.

[5] Bate-Smith, S. (1992). Flavonoid compounds comparative Biochemistry III. New York academic press pg 75-89.

[6] Bocobza, S. and Aharoni, A. (2008). Switching the light on plant Phenols. Trends in Plant Science Journal 13 (10). $526-533$

[7] Boham, A. B. and Kocipai, A. C (1994) Flavonoid and condensed tannins from Leaves of Hawaiian vaccininum vaticulum and vicalycinium. Pacific Science, 48:458-463.

[8] Butterworth,R.F. (2006).Modern Nutrtion in health and disease $10^{\text {th }}$ ed.Wiliam and Wilkins prints,Baltimore.

[9] Coe, F. L., Evan, A. and Worcester, E. (2005).Kidney Stone Disease. Journal of clinical investigation, 115(10): 2598-2608.

[10] Combs G. F (2008). The vitamins, Fundamental aspects in nutrition and health ( $3^{\text {rd }}$ ed. Elseviver academic press Berlington

[11] Cordell G. A. (2001). The Alkaloids chemistry and Biology vol. 56 Elsevier press, Montreal, 75-54

[12] Dea, U. V. (2002). Biosynthesis of flavonoids and its structural components.. Journal of Biological science, 204: 13-15.

[13] Duster, G. (2008). "Retinoic acid synthesis and signaling during organogenesis" Cell, 134 (6): 921-931.

[14] Ericksen, B. R. (2000) Nutrition and human metabolism. Wadsworth learners, Arizona ,67-80.

[15] Fabricant, D. S. and Farnswoth N. R (2001). The value of plants used in traditional medicine for drug discovery. Environmental Health Perspective, 109(1): 69-75.

[16] Ferrell, K. E and Thorington R.W. (2006). Squirrels the animal answer guide John Hopkins university press, Baltimore, 91.

[17] Francis, G., Zohar K.H, Makker, P. S. and Klaus, B. (2002). The Biological action of saponins in animal system "British Journal of Nutrition, 88 (6): 587-605.

[18] George, D. and Pampleona, R. (2002). Encyclopedia of medicinal plants. La mina Press, Spain ,10.

[19] Giffths, D. W. (1999). The inhibition of enzymes by extracts of field beans (vicia faba). Journal of Science for Food Agriculture, 30: 458-462.

[20] Harborne, J. B. (1973). Phytochemical Methods, Chapman and Hall, London 113.

[21] Hostettmann, K. and Marston, A. (1995). Saponins Cambridge University Press , Cambridge, 355

[22] George, D. and Pampleona, R. (2002). Encyclopedia of medicinal plants

[23] La mina Press, Spain, 10

[24] Lai, P. K. and Roy, J. (2004). Antimicrobial and Chemopreventive properties of herbs and spices Current medicinal chemistry ; 11(1): 431-1460.

[25] Mcguire M, and Beerman K.A (2007). Nutritional Science from fundamentals to food. Thomson Wadsworth Belmont

[26] Nelson, A. Jenkins O. and Merran. P (2008). Neutrophil gelatinase associated lipocasin mediates B-cis retinoic acid-induced apotosis of human sebaceous gland cells. Journal of Clinical Investigation; 118(8): 1468-1472.

[27] Obadoni, B. O. and Ochuko, P. O. (2001). Phytochemical studies and Comparative efficacy of the crude extracts of some homeostatic plants in Edo and Delta States of Nigeria. Global Journal for Pure Applied Science, 8: 203-208.

[28] Ofokansi, K.C., Esimone, C.O. and Anele C. K. (2005). Evaluation of the in vitro combined anti bacterial effects of the leaf extracts of Bryophyllum pinnatum. (Fam: crassulaceae) and Ocimum gratissium (Fam:Labiate). Plant Production Research. Journal, 9: 2327.

[29] Ojewole, J. (2005). Antinociceptive, anti-inflammatory and antidiabetic effects of Bryophyllum pinnatum (Crassulaceae) leaf aqueous extract. Journal of Ethno-pharmacology, 99: 13-19.

[30] Okwu, D. E. (2001). Phytochemicals and vitamin content of indigenous spices of Southeastern Nigeria. Journal for Sustaining Agricultural Environment. 6(1): 30- 37.

[31] Okwu, D. E. (2003). Efficacy of B. pinnatum. .Nigeria Agricultural.Journal, 34: 143- 148 .

[32] Okwu, D. E. and Okwu, M. E. (2004). Chemical Composition of Spondiasmombin linn plant parts. Journal for Sustaining Agricultural Environment, 6(2): 140-147.

[33] Onwuka, G. I (2005). Food Analysis and Instrumentation theory and Practice Napthalis prints, Nigeria ,146.

[34] Schmitt, A. C., Almeida, A. B., Silveira, T. A.,. Iwakura, C. T., Mendes, K.. F. and Silva, M. C. (2003). Invitro antibacterial activity of Bryophyllum pinnatum ('Folha-da-fortuna') leaves from Varzea Grande, Mato Grosso/Brazil. Science Veterinary, 31(1): 55-58.

[35] Solomon N.W, and Orozco, M (2003). "Allevation of Vitamin A Deficiency with Palm Fruits and its Product." Clinical Nutrition ; 12 (3) 373-384

[36] Stanley, B. (2009). Recognition and Respect for Africa Traditional Medicine. Journal of opinion, 9(3): 25-28.

[37] Veselovskaya, N. B. and Kovalenko, A. E. (2000). Effects of Alkaloids. Drugs, 9: 11-12

[38] Zingg, A. A. (2004). "Non-antioxidant activities of vitamin E". Current medicinal Chemistry 11 (9): $1113-1133$. 